\title{
Exploring dysmenorrhoea and menstrual experiences among Lebanese female adolescents
}

\author{
T. Santina, ${ }^{7}$ N. Wehbe ${ }^{2}$ and F. Ziade ${ }^{3}$
}

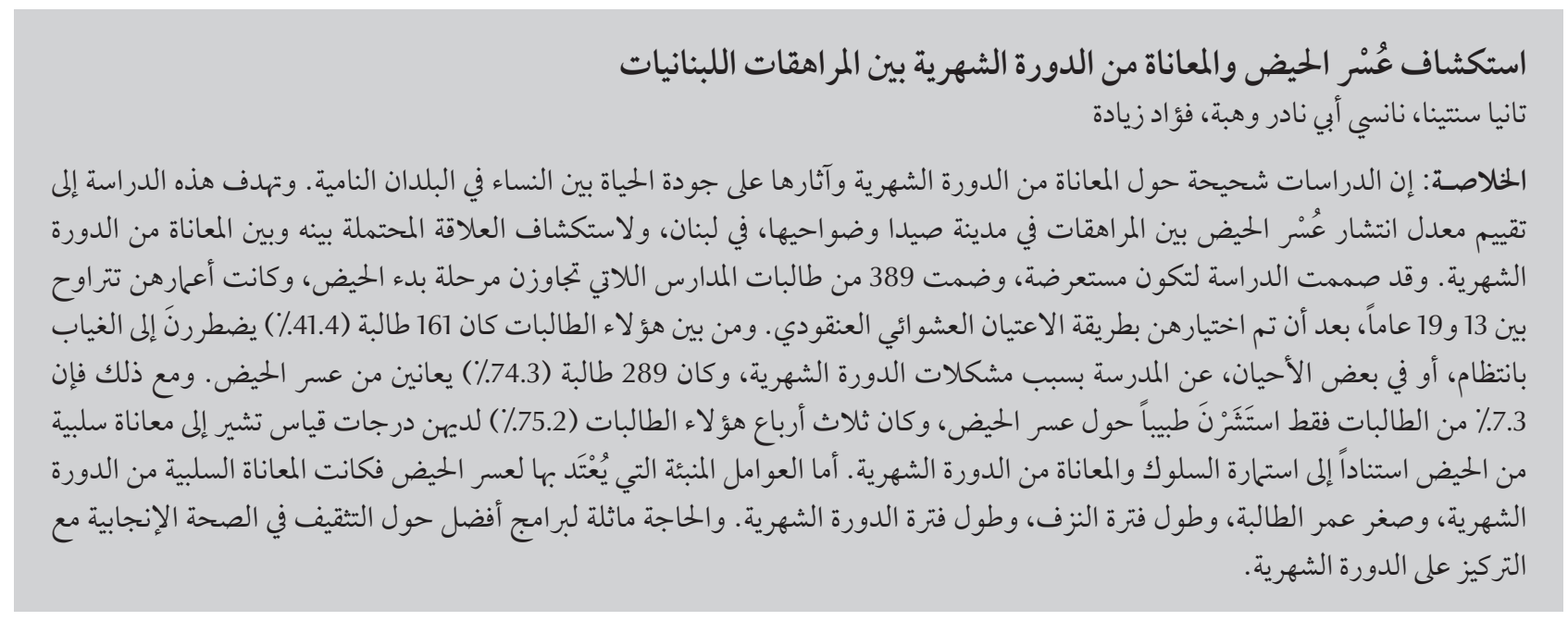

ABSTRACT Data on menstrual experiences and their impact on quality of life among women in developing countries are scant. The aim of this study was to assess the prevalence of dysmenorrhoea among adolescent girls in Sidon city and suburbs, Lebanon, and to explore its possible relationship with menstrual experience. In a cross-sectional design, 389 post-menarcheal schoolgirls aged 13-19 years were selected using a cluster random sampling method. Of these 161 (41.4\%) were regularly or sometimes absent from school due to menstrual problems and 289 (74.3\%) experienced dysmenorhoea. Nevertheless only $7.3 \%$ of the girls had consulted a physician about dysmenorrhoea. Three-quarters of these young women $(75.2 \%)$ had scores indicating negative menstrual experience based on the Menstrual Experience and Behavior Questionnaire. Significant predictors of dysmenorrhoea were negative menstrual experience, younger age of girl, longer duration of bleeding and longer cycle length. Better reproductive health educational programmes focusing on menstruation are needed for female adolescents.

\section{Étude de la dysménorrhée et du vécu des menstruations chez des adolescentes libanaises}

RÉSUMÉ Les données sur le vécu des menstruations des femmes dans les pays en développement et son impact sur leur qualité de vie sont rares. L'objectif de la présente étude était d'évaluer la prévalence de la dysménorrhée chez des adolescentes à Saïda et sa banlieue (Liban) et d'examiner un lien potentiel avec le vécu des menstruations.Une étude transversale a été menée auprès de 389 adolescentes réglées, âgées de 13 à 19 ans et sélectionnées par échantillonnage aléatoire en grappes. Parmi celles-ci, 161 (41,4\%) s'absentaient régulièrement ou occasionnellement de l'école en raison de troubles menstruels et 289 (74,3\%) souffraient de dysménorrhée. Toutefois, seules $7,3 \%$ des filles avaient consulté un médecin au sujet de la dysménorrhée. Les trois quarts de ces jeunes filles (75,2\%) ont obtenu des scores indiquant un vécu négatif des menstruations selon le Menstrual Experience and Behavior Questionnaire. Parmi les facteurs prédictifs importants de dysménorrhée, on peut citer un vécu négatif des menstruations, la jeunesse, une longue durée de saignements et un long cycle. De meilleurs programmes d'éducation en santé génésique axés sur les menstruations sont nécessaires pour les adolescentes. 


\section{Introduction}

Menstruation is a natural phenomenon which is an important indicator of women's health $[1-3]$, reflecting as it does their endocrine function [4]. However, data on experiences of menstruation and its impact on the health status, quality of life and social integration among women in developing countries are scant [5]. Dysmenorrhoea, for example, is a common problem, yet it remains poorly understood and is rarely taken into consideration when assessing adolescents' health and life experiences [1]. Pain or cramping sensations in the lower abdomen may be accompanied by headaches, dizziness, diarrhoea, a bloated feeling, nausea and vomiting, backache and leg pains [2,5-8]. These symptoms are reported to be the most common reasons for adolescents visiting a gynaecologist $[2,4,5]$. The high prevalence of dysmenorrhoea among adolescents (50\%-70\%) [6,8-10], especially in the first years of their reproductive life $[2,6]$, influences their daily activities and can lead to high rates of school absenteeism [2,4-6,10,11], and is thus a major public health problem [12].

Attitudes to menstruation are also poorly understood. Anxiety, fear, anger, confusion, shame, disgust and even depression are frequently reported by girls during their first menstrual experiences [1]. Previous research findings have suggested a significant relation between menstrual experiences and sociocultural aspects, such as ethnical background, urbanization, education and occupation, among others [13]. In addition, perpetuations of cultural menstrual taboos and messages, such as menstruation as a shameful and dirty situation or as something intimidating, may have direct or indirect negative inferences on the beliefs of girls at menarche and therefore on their future menstrual experiences [1].
To the best of our knowledge, studies on dysmenorrhoea and menstrual experiences in Lebanese adolescent girls are scarce [9]. The aims of this study were to assess the prevalence of dysmenorrhoea among schoolgirls in Sidon city and its suburbs and to explore the relationship between menstrual experiences and dysmenorrhoea.

\section{Methods}

\section{Study design and sample}

This was a descriptive, cross-sectional study. A cluster random sampling technique was used to select the schools; all the students within the selected schools were recruited. First, a list of all the schools in Sidon city, Lebanon, and its suburbs was obtained from of the Ministry of Education and Higher Education, Centre for Educational Research and Development. Inclusion criteria for the schools were being a high school and providing education in English language (16 schools, $n=2792$ schoolgirls). Five schools that could not afford the administrative requirements of the study in terms of time, procedures and personnel needed to address the study's objectives were excluded. Of the 11 eligible schools a cluster random sampling technique was used to select 5 Englisheducation high schools. Secondly, all post-menarcheal schoolgirls in grades 8 to 12 (age 13-19 years) in the 5 selected schools were included in this study ( $n=435$ schoolgirls). Women who were married or engaged were excluded to avoid confounding factors due to sexual relationships. There were 36 girls who did not meet the inclusion criteria and 9 refused to participate and so a total number of 389 girls participated, completed the questionnaire and were included in the final analysis of this study, yielding a response rate of $97.7 \%$.

\section{Data collection}

\section{Field procedures}

The study protocol was examined and approved by the ethical review board of the Lebanese Ministry of Education. An envelope including a covering letter, an information leaflet containing the purpose of the study and a consent form were given to all students and their parents before conducting the study. Participants knew the purpose of the study and were assured of confidentiality. They were also reassured of their right to withdraw from the study at any time without any consequence and that the data would be used solely for the purpose of academic research.

The study took place over a period from February 2010 to March 2010. During this process, a female teacher was present in schools in an effort to maintain the confidentiality of the collected data. On average the students needed 25 minutes to complete the questionnaire.

\section{Study instrument}

The schoolgirls answered a self-administered, structured questionnaire including sociodemographic data (age, nationality, religion, age of menarche, school grade, position in the family, parents' educational level and family monthly income) as well as the Menstrual Experience and Behavior Questionnaire (MEBQ) designed by McPherson and Korfine [1]. The MEBQ is a validated scale with a Cronbach alpha of 0.87 . The questionnaire was printed and distributed in its original English language version. With permission from the original developer of the questionnaire 4 questions related to sexual behaviour were deleted (Q14, Q18, Q19, Q20) in order to adapt the questionnaire to the Lebanese cultural preferences. Furthermore, we reorganized 3 questions concerning the duration of cycles, duration of menses and physical aspects 
of periods, based on the result of 2 pretests done among 33 schoolgirls. Two parts from the MEBQ were used in the questionnaire:

- Menstrual cycle characteristics. Five questions covered topics including: the characteristics of a "usual" menstrual period in terms of regularity, duration and heaviness, the pain experienced with menstruation and frequency and quality of menstrual periods.

- Menstrual experience. According to the original authors of the scale [1], 6 questions were used to assess how adolescents currently experience their menstrual cycles and their bodies. Each question has a negative or positive response, with negative terms coded 0 and positive terms coded 1 . The scores on the 6 items were added to give a total score (between 0-6) for each girl and the mean total score was calculated for the sample. For each girl the mean score on the 6 items formed a composite score (between 0-1) where 1 reflected more positive overall experiences. The cut-off point of 0.5 in this composite score was used to divide the schoolgirls into 2 groups: negative menstrual experience (score $0-0.5)$ and positive menstrual experience $($ score $>0.5-1)$.

\section{Statistical analysis}

Data are presented in tables reporting frequencies and means and standard deviation (SD) as appropriate. The chi-squared test was used to perform bivariate comparisons between the prevalence of dysmenorrhoea and the different sociodemographic characteristics, menstrual characteristics and menstrual experience. Factors affecting the prevalence of dysmenorrhoea were entered into a multivariate logistic regression analysis in order to explore predictor factors of dysmenorrhoea. The sample size recruited in this study was sufficient to detect a difference in the duration of bleeding of 0.17 between the 2 study groups (dysmenorrhoea versus no dysmenorrhoea) with $\alpha=0.05$ and power > 0.90 .

SPSS software, version 16.0 was used for data analysis. $P<0.05$ was considered as statistically significant.

\section{Results}

\section{Demographic and menstruation characteristics}

A total of 389 schoolgirls completed the questionnaire. The participants' demographic data are presented in Table 1 . The mean age of menarche was 12.5 (SD 1.0) years (range 9-15 years), with $85.9 \%$ of girls experiencing menarche between ages 11-13 years.

The mean cycle length was 26.4 days and the average duration of menses was 6 days. Duration of menses was $\leq 6$ days for $44.7 \%$ and $\geq 7$ days for $55.3 \%$. One-third of the respondents $(35.2 \%)$ reported having irregular menstrual cycles (Table 2) and 27.0\% that the amount of blood flow was heavy.

A total of 161 girls (41.4\%) had sometimes or regularly missed days from schools in the previous year due to menstruation; $12.3 \%$ regularly missed school on the first day of their period and $4.9 \%$ on the first 2 days of their period (Table 2). Only 29 schoolgirls (7.5\%) stated that they had consulted a physician for menstrual disorders (3.6\%), genital infection (2.1\%) or ovarian cyst (1.8\%).

Dysmenorrhoea was reported by $289(74.3 \%)$ of the participants with premenstrual symptoms including abdominal pain (37.0\%), headaches (22.8\%), breast swelling (34.6\%), back pain (19.4\%), leg pain (15.6\%), breast pain $(6.6 \%)$, general body aches (22.8\%), mood changes (80.7\%) and/ or irritability (72.0\%). Of these, only 21 girls $(7.3 \%)$ had consulted a physician about dysmenorrhoea. The great majority of girls who missed schools days because of menstruation suffered from menstrual pain $(87.5 \%$ of those who missed 1 day per month and $84.2 \%$ of those who missed 2 days per month) (Table 2).

\section{Experiences of menstruation}

The mean total score on the MEBQ for all participants was 1.93 (SD 1.0), on a scale of $0-6$ ). Of the 389 girls who answered the MEBQ, 287 (73.8\%) had negative menstrual experience scores (Table 2).

Among 389 schoolgirls who described their menstruation, $97.0 \%$ used negative words like "disgusting" (30.5\%), "painful" (9.1\%), "bad" (8.8\%), "I hate it" (5\%), "It's hard" (3.9\%), "depressing" (3.8\%), "[like a] disease" (3.4\%), "tiring" (3.4\%), "I wish I never had it" (0.9\%), "ridiculous" (0.9\%), "[like a] virus", "terrible”, "embarrassing" (0.6\%) and others (0.3\%).

\section{Associations of demographic/ menstruation characteristics with dysmenorrhoea}

Table 2 shows the chi-squared analysis of the association between the girls' demographic/menstruation characteristics and presence of dysmenorrhoea. Dysmenorrhoea was significantly associated with missing school days $(P=$ $0.03)$ and with negative menstrual experience scores $(P<0.001)$ (Table 2$)$. There were also significant relationships between dysmenorrhoea and younger age $(P<0.001)$, longer cycle length $(P<0.001)$, duration of menses $(P<$ $0.001)$ and suffering mood changes $(P$ $<0.001)$. However, there were no significant associations between dysmenorrhoea and schoolgirls' family income, cycle regularity or extent of menstrual flow.

The results of multiple logistic regression with dysmenorrhoea as the dependent variable show that the risk of dysmenorrhoea was significantly higher in girls having a negative 


\begin{tabular}{|c|c|c|}
\hline Variable & No. & $\%$ \\
\hline \multicolumn{3}{|l|}{ Age (years) } \\
\hline Mean (SD) & $15.8(1.4)$ & \\
\hline \multicolumn{3}{|l|}{ Nationality } \\
\hline Lebanese & 341 & 87.7 \\
\hline Palestinian & 48 & 12.3 \\
\hline \multicolumn{3}{|c|}{ Years since menarche $(n=387)^{a}$} \\
\hline 1 & 4 & 1.0 \\
\hline 2 & 26 & 6.7 \\
\hline 3 & 58 & 14.9 \\
\hline 4 & 81 & 20.8 \\
\hline 5 & 82 & 21.1 \\
\hline 6 & 74 & 19.0 \\
\hline 7 & 38 & 9.8 \\
\hline 8 & 20 & 5.1 \\
\hline 9 & 4 & 1.0 \\
\hline Data unclear & 2 & 0.5 \\
\hline \multicolumn{3}{|l|}{ School grade } \\
\hline 8th & 91 & 23.4 \\
\hline 9th & 91 & 23.4 \\
\hline 10th & 105 & 27.0 \\
\hline 11th & 57 & 14.7 \\
\hline 12th & 45 & 11.6 \\
\hline \multicolumn{3}{|c|}{ Father's education } \\
\hline Primary & 65 & 16.7 \\
\hline Elementary & 104 & 26.7 \\
\hline Secondary & 87 & 22.4 \\
\hline University & 133 & 34.4 \\
\hline \multicolumn{3}{|c|}{ Mother's education } \\
\hline Primary & 35 & 9.0 \\
\hline Elementary & 103 & 26.5 \\
\hline Secondary & 120 & 30.8 \\
\hline University & 131 & 33.6 \\
\hline \multicolumn{3}{|c|}{ Monthly family income (US\$) } \\
\hline$<1000$ & 59 & 15.2 \\
\hline 1000-2000 & 145 & 37.3 \\
\hline 2000-300 & 101 & 26.0 \\
\hline$>3000$ & 84 & 21.6 \\
\hline
\end{tabular}

${ }^{a}$ Variable derived from subtracting the current age of schoolgirls and their age at menarche. $S D=$ standard deviation

menstrual experience score $(\mathrm{OR}=$ 9.99; 95\% CI: 4.29-23.3), younger age of girl $(\mathrm{OR}=2.18 ; 95 \% \mathrm{CI}: 0.91-5.21)$ and longer duration of bleeding $(\mathrm{OR}=$ 4.15 ; $95 \%$ CI: $1.61-10.7)$ or longer cycles $(\mathrm{OR}=3.10 ; 95 \% \mathrm{CI}: 1.27-7.54)$ (Table 3). during adolescence [11] and influence body image and female sexual identity [14].

Similar to other countries in the world $[8,15]$, the mean onset of menarche of Lebanese girls is declining, and the mean age at menarche in the present study is lower than that identified in southern Lebanese women in 1996 [13.6 (SD 1.7) years ] [16]. The findings are also similar to those reported in another recent study in Lebanon [12.3 (SD 0.9) years] [17], as well as in the Islamic Republic of Iran [12.3 (SD 1.1) years] [18], Saudi Arabia [12.0 (SD 1) years] [19], Taiwan [12.3 (SD 1.1 years] [7], Hong Kong [12.3 (SD 1.1) years] [20] and Malaysia [12.3 (SD 1.1) years] [21].

The irregularity of cycles occurring in $35.2 \%$ of the sample is similar to the results of an Egyptian study (33.2\%) [5] but is higher of the results of a Nigerian study (9\%) [22].

The prevalence of dysmenorrhoea $(74.3 \%)$ among schoolgirls in this study is similar to results of other studies (ranging from $67.7 \%$ to $76.0 \%$ ) $[1,2,5,8,14,19,23,24]$, but higher than results from Nigeria and Taiwan (60.0\% and $60.5 \%$ respectively) $[6,25]$.

Furthermore, dysmenorrhoea is a leading cause of short-term school absenteeism among young women. As many as $41.4 \%$ of girls in this study regularly or sometimes missed days from school and $4.9 \%$ regularly missed 2 days each month (i.e. up to 24 days per school year) because of their menstrual period. Most of these girls suffered from dysmenorrhoea. This percentage is lower than that found in Saudi Arabian adolescents (61.7\%) [21] and higher than those found in various other researches (ranging from $12.5 \%$ to $25.8 \%$ ) $[2,6,7,9,10,24]$.

The literature contains a large number of findings about menstruation as a negative psychological experience and as a time when women must cope with considerable psychological and 


\begin{tabular}{|c|c|c|c|c|c|c|}
\hline \multirow[t]{2}{*}{ Variable } & \multirow[t]{2}{*}{ Total } & \multicolumn{4}{|c|}{ Dysmenorrhoea } & \multirow[t]{2}{*}{$P$-value } \\
\hline & & Yes & $\%$ & No & $\%$ & \\
\hline Age (years) & & & & & & 0.023 \\
\hline $13-15$ & 150 & 121 & 80.7 & 29 & 19.3 & \\
\hline $16-19$ & 239 & 168 & 70.3 & 71 & 29.7 & \\
\hline Monthly family income (US\$) & & & & & & 0.27 \\
\hline$<1000$ & 59 & 38 & 64.4 & 21 & 35.6 & \\
\hline $1000-2000$ & 145 & 111 & 76.6 & 34 & 23.4 & \\
\hline $2000-3000$ & 101 & 78 & 77.2 & 23 & 22.8 & \\
\hline$>3000$ & 84 & 62 & 73.8 & 22 & 26.2 & \\
\hline Length of menstrual cycle (days) & & & & & & 0.328 \\
\hline$\leq 28$ & 167 & 132 & 79.0 & 35 & 21.0 & \\
\hline$\geq 29$ & 71 & 52 & 73.2 & 19 & 26.8 & \\
\hline Regularity of menstrual cycle & & & & & & 0.590 \\
\hline Regular & 252 & 185 & 73.4 & 67 & 26.6 & \\
\hline Irregular & 137 & 104 & 75.9 & 33 & 24.1 & \\
\hline Extent of menstrual flow & & & & & & 0.159 \\
\hline Heavy & 105 & 84 & 80.0 & 21 & 20.0 & \\
\hline Moderate & 176 & 131 & 74.4 & 45 & 25.6 & \\
\hline Light & 108 & 74 & 68.5 & 34 & 31.5 & \\
\hline Duration of menses (days) & & & & & & $<0.001$ \\
\hline$\leq 6$ & 174 & 149 & 85.6 & 25 & 14.4 & \\
\hline$\geq 7$ & 215 & 140 & 65.1 & 75 & 34.9 & \\
\hline School absenteeism due to menstruation & & & & & & 0.031 \\
\hline Regularly (1st day of period) & 48 & 42 & 87.5 & 6 & 12.5 & \\
\hline Regularly (1st and 2nd days of period) & 19 & 16 & 84.2 & 3 & 15.8 & \\
\hline Sometimes & 94 & 73 & 77.7 & 21 & 22.3 & \\
\hline Never & 228 & 158 & 69.3 & 70 & 30.7 & \\
\hline Mood changes at menstruation & & & & & & $<0.001$ \\
\hline Yes & 314 & 246 & 78.3 & 68 & 21.7 & \\
\hline No & 75 & 43 & 57.3 & 32 & 42.7 & \\
\hline Menstrual experience ${ }^{a}$ & & & & & & $<0.001$ \\
\hline Negative & 287 & 255 & 88.2 & 32 & 32.1 & \\
\hline Positive & 102 & 34 & 11.8 & 68 & 68.0 & \\
\hline
\end{tabular}

${ }^{a}$ Based on mean scores on the Menstrual Experience and Behavior Questionnaire [1].

physical changes [1]. It is described as a traumatic experience for some women, which can even affect their future life prospects [11]. It has been found that women suffering from dysmenorrhoea are more predisposed to psychological disorders such as mood changes [1], depression, anxiety and somatization [9]. In this study $80.7 \%$ of girls reported suffering mood changes at menstruation. Dysmenorrhoea has previously been described in negative terms among adolescents and is significantly associated with negative menstrual experiences [1]. In addition, many of the schoolgirls in our study reported that they experienced headaches, fatigue, back pain; vomiting, diarrhoea and dizziness during menstruation. These symptoms are commonly cited in the literature $[8,19,21]$. Given the frequency of these symptoms, health care providers should consider enquiring about menstrual symptoms including dysmenorrhoea [8].

Despite the high proportions suffering from dysmenorrhoea, only $7.3 \%$ of girls in our study had sought medical advice. This figure is lower than those obtained in a Malaysian study (12.0\%) [24], in Nigeria (17.9\%) [26] and in the Islamic Republic of Iran (18\%) [2], which suggests that culture may influence the experience and interpretation of symptoms such as pain and the ways 


\begin{tabular}{|c|c|c|c|c|}
\hline Variable & $\beta$ & $P$-value & OR & $95 \% \mathrm{Cl}$ \\
\hline Age $13-15$ vs $16-19$ years & 0.778 & 0.08 & 2.18 & $0.91-5.21$ \\
\hline Duration of menses $\geq 7$ vs $\leq 6$ days & 1.422 & 0.003 & 4.15 & $1.61-10.7$ \\
\hline Length of cycle $\geq 29$ vs $\leq 28$ days & 1.131 & 0.013 & 3.10 & $1.27-7.54$ \\
\hline Menstrual experience negative vs positive & 2.302 & $<0.001$ & 9.99 & $4.29-23.3$ \\
\hline
\end{tabular}

Model fit $=82.8 \%,-2$ log likelihood $=147.29, \chi^{2}=54.691, P<0.001$

$O R=$ odds ratio; $C l=$ confidence interval.

in which they are treated. Other studies have recommended that young women consult a specialist for pain relief and for managing dysmenorrhoeal symptoms [27].

This study provided some important indications of factors associated with dysmenorrhoea. We showed that the risk of dysmenorrhoea was significantly higher in girls in the early years of menarche, with prolonged cycles and heavy menstrual flow, as found in a study in Egypt [5], and in participants with negative menstrual experience scores, as shown also in Nigeria [26]. Furthermore, mood changes and school absenteeism were more common in those suffering from dysmenorrhoea.

The findings of the present study, derived from a small sample recruited in a local population within a particular cultural context, need to be substantiated with further studies using a large sample size drawn from different regions of Lebanon. Future researches should combine quantitative and qualitative methods, within longitudinal experimental designs, in order to explore changes in the perimenarcheal phase, and the effects of educational programmes on dysmenorrhoea management.

Nevertheless, this study provided useful information about menstrual health care issues among Lebanese schoolgirls and warrants more attention in the public health agenda, thus helping health professionals to plan and develop strategies for improving reproductive health among adolescents.

\section{Conclusions}

Menstrual pain and other adverse symptoms were common in our sample of Lebanese teenagers. Health professionals are invited to initiate appropriate steps to raise awareness in the community and to update school curricula by educating schoolgirls regarding this important health issue.
A high proportion of girls were absent from school and very few schoolgirls had sought medical help for dysmenorrhoea. Girls indicating moderate to severe pain in association with a high number of menstrual symptoms, school absence and interference with life activities should be effectively managed, or referred for further investigation, to minimize menstrual morbidity.

\section{Acknowledgements}

We are indebted to the authorities of the Sidon School Network in Sidon city and its Suburbs, the Director of the Sexual and Reproductive Health Program at the Ministry of Social Affairs, Ms Joumana El-Kadi, the schools and the students for kindly cooperating with us in collecting the data. Also we express our gratitude to the Antonine University represented by the Department of Nursing and all its members.

\section{References}

1. McPherson ME, Korfine L. Menstruation across time: menarche, menstrual attitudes, experiences, and behaviors. Women's Health Issues, 2004, 14:193-200.

2. Poureslami M, Osati-Ashtiani F. Attitudes of female adolescents about dysmenorrhea and menstrual hygiene in Tehran suburbs. Archives of Iranian Medicine, 2002, 5:219-224.

3. Nelson LM et al. The menstrual cycle-getting the "vital" respect it deserves. Thousand Oaks, California, Pituitary Network Association, 2003 (http://www.pituitary.org/library/library_detail. aspx?page_id=1495, accessed 4 July 2012).

4. Sanyal S, Ray S. Variation in the menstrual characteristics in adolescents of West Bengal. Singapore Medical Journal, 2008, 49:542-550.
5. El-Gilany AH, Badawi K, El-Fedawy S. Epidemiology of dysmenorrhoea among adolescent students in Mansoura, Egypt. Eastern Mediterranean Health Journal, 2005, 11:155-163.

6. Esimai OA, Esan GO. Awareness of menstrual abnormality amongst college students in urban area of Ile-Ife, Osun state, Nigeria. Indian Journal of Community Medicine, 2010, 35:63-66.

7. Titilayo A et al. Menstrual discomfort and its influence on daily academic activities and psychosocial relationship among undergraduate female students in Nigeria. Tanzania Journal of Health Research, 2009, 11:181-188.

8. Banikarim C, Chacko MR, Kelder SH. Prevalence and impact of dysmenorrhea on Hispanic female adolescents. Archives of Pediatrics \& Adolescent Medicine, 2000, 154:1226-1229. 
9. Chen $\mathrm{HM}$, Chen $\mathrm{CH}$. Related factors and consequences of menstrual distress in adolescent girls with dysmenorrhea. $\mathrm{Ka}$ ohsiung Journal of Medical Sciences, 2005, 21:121-127.

10. Houston AM et al. Knowledge, attitudes, and consequences of menstrual health in urban adolescent females. Journal of Pediatric and Adolescent Gynecology, 2006, 19:271-275.

11. Harlow SD, Campbell OM. Epidemiology of menstrual disorders in developing countries: a systematic review. British Journal of Obstetrics and Gynaecology, 2004, 111:6-16.

12. Parker MA, Sneddon AE, Arbon P. The menstrual disorder of teenagers (MDOT) study: determining typical menstrual patterns and menstrual disturbance in a large population-based study of Australian teenagers. British Journal of Obstetrics and Gynaecology, 2010, 117:185-192.

13. Dorn LD et al. Menstrual symptoms in adolescent girls: association with smoking, depressive symptoms, and anxiety. Journal of Adolescent Health, 2009, 44:237-243.

14. French L. Dysmenorrhea. American Family Physician, 2005, 71:285-291.

15. Marvan ML, Vacio A, Espinosa-Hernandez G. A comparison of menstrual changes expect by pre-menarcheal and postmonarchial adolescents in Mexico. Journal of School Health, 2001, 71:458-461.

16. Chang YT, Chen YC. Menstrual health care behavior and associated factors among female elementary students in the Hualien region. Journal of Nursing Research, 2008, 16:8-16.

17. Wiksten-Almströmer M, Hirschberg AL, Hagenfeldt K. Menstrual disorders and associated factors among adolescent girls visiting a youth clinic. Acta Obstetricia et Gynecologica Scandinavica, 2007, 86:65-72.

18. Hannoun AB et al. Effect of war on the menstrual cycle. Obstetrics and Gynecology, 2007, 109:929-932.
19. El Hage R et al. Indice de masse corporelle et ultrasonographie quantitative osseuse des phalanges chez des adolescentes libanaises réglées [Body mass index and phalangeal osteosonogrammetry in Lebanese post-menarcheal adolescent girls]. Journal of the Medical Library, 2010, 58:12-17.

20. Mohammadzadeh $\mathrm{Z}$ et al. Puberty health education in Iranian teenagers: Self-learning or lecture and discussion panel? Iranian Journal of Medical Education, 2002, 3:4-7.

21. Moawed S. Indigenous practices of Saudi girls in Riyadh during their menstrual period. Eastern Mediterranean Health Journal, 2001, 7:197-203.

22. Chan SS et al. Menstrual problems and health-seeking behaviour in Hong Kong Chinese girls. Hong Kong Medical Journal, 2009, 15: 451-456.

23. Lee LK et al. Menstruation among adolescent girls in Malaysia: a cross-sectional school survey. Singapore medicine journal, 2006. 47:869-874.

24. Wong LP, Khoo EM. Dysmenorrhea in a multiethnic population of adolescent Asian girls. International Journal of Gynaecology and Obstetrics, 2010, 108:139-142.

25. Lu ZYJ. The relationship between menstrual attitudes and menstrual symptoms among Taiwanese omen. Journal of advanced nursing, 2001, 33:622-623.

26. Sule ST, Ukweny JE. Menstrual experiences of adolescents in a secondary school. Journal of the Turkish-German Gynecology Association, 2007, 8:7-14.

27. Algies pelviennes, Item 292-Module 11. Campus National de Gynécologie Obstétrique, 2004 [online] (http://Imm.univlyon1.fr/internat/download/item292b.pdf, accessed 4 July 2012) 